\title{
A Li-rich layered-spinel cathode material for high capacity and high rate lithium-ion batteries fabricated via a gas-solid reaction
}

\author{
Lingqun $\mathrm{Xu}^{1,3 \dagger}$, Zhenhe $\mathrm{Sun}^{2 \dagger}$, Yu $\mathrm{Zhu}^{2}$, Yu Han ${ }^{2}$, Manman $\mathrm{Wu}^{2}$, Yanfeng $\mathrm{Ma}^{2,3}$, Yi Huang ${ }^{3}$, \\ Hongtao Zhang ${ }^{2,3^{*}}$ and Yongsheng Chen ${ }^{2,3^{*}}$
}

\begin{abstract}
Lithium-rich layered oxide (LLO) cathode materials have drawn extensive attention due to their ultrahigh specific capacity and energy density. However, their commercialization is still restricted by their low initial coulombic efficiency, slow intrinsic kinetics and structural instability. Herein, a facile surface treatment strategy via gaseous phosphine was designed to improve the rate performance and capacity stability of LLOs. During the solid-gas reaction, phosphine reacted with active oxygen at the surface of LLOs due to its reductivity, forming oxygen vacancies and spinel phase at the surface region. As a result, Li ion conductivity and structural stability were greatly enhanced. The phosphinetreated LLOs (LLO@P) showed a layered-spinel hybrid structure and delivered an outstanding rate performance of $156.7 \mathrm{~mA} \mathrm{~h} \mathrm{~g}^{-1}$ at $10 \mathrm{C}$ and a high capacity retention of $74 \%$ after 300 cycles at $5 \mathrm{C}$.
\end{abstract}

Keywords: cathode materials, Li-rich, layered-spinel structure, high rate performance, phosphine

\section{INTRODUCTION}

Lithium-ion batteries (LIBs) are considered to be one of the most promising energy storage devices for electric vehicles due to their high energy density and long life span $[1,2]$. However, further improvement in energy density is necessary for their applications in electric vehicles and storage systems [3-5]. The practical capacity of cathode materials is the key factor influencing the energy density of LIBs [6]. Li-rich layered oxide (LLO) cathode materials have been brought into focus due to their ultrahigh specific capacity and energy density (Fig. S1) [6-9].
However, there are still some challenges which restrict the industrialization and commercial applications of LLOs $[10,11]$, including poor kinetics, inferior structural stability and low initial coulombic efficiency [12-14]. LLOs consist of rhombohedral $\mathrm{LiMO}_{2}(\mathrm{M}=\mathrm{Mn}, \mathrm{Ni}$ or Co) phase and monoclinic $\mathrm{Li}_{2} \mathrm{MnO}_{3}$ phase $[15,16]$. The special oxygen anion redox process provides LLOs with a high specific capacity of over $300 \mathrm{~mA} \mathrm{~h} \mathrm{~g}^{-1}$ [1]. However, oxygen is easily and irreversibly extracted from the crystal structure during the active processes of $\mathrm{Li}_{2} \mathrm{MnO}_{3}$, which simultaneously destroys the crystal structure of LLOs and leads to large irreversible specific capacity as well as low initial coulombic efficiency [17-19]. Furthermore, the released oxygen can react with electrolyte and generate various byproducts, which accelerates the accumulation of inert components and increases the internal impedance $[1,20,21]$. Besides, LLOs show poor kinetics due to the introduction of $\mathrm{Li}_{2} \mathrm{MnO}_{3}$ component with inferior ion and electron conductivities [13]. As a result, the rate performance and cycle stability of LLOs need to be further improved for their commercialization.

Since oxygen release is closely related to the surface structure of LLOs, surface engineering strategies have been widely used to enhance the electrochemical performance of LLOs [3]. It has been reported that $\mathrm{NH}_{3}$ and $\mathrm{CO}_{2}$ can react with LLOs to reduce the oxygen partial pressure and inhibit oxygen release [20,22]. Moreover, the increase of oxygen vacancies can induce the formation of spinel structure at the surface region to enhance the $\mathrm{Li}$ ion conductivity. Our group also developed a facile gaseous sulfur treatment strategy to modify the surface

\footnotetext{
${ }^{1}$ School of Materials Science and Engineering, Nankai University, Tianjin 300071, China

${ }^{2}$ The Centre of Nanoscale Science and Technology and Key Laboratory of Functional Polymer Materials, Nankai University, Tianjin 300071, China

${ }^{3}$ The National Institute for Advanced Materials, Nankai University, Tianjin 300071, China

$\dagger$ These authors contributed equally to this work.

* Corresponding authors (emails: yschen99@nankai.edu.cn (Chen Y); htzhang@nankai.edu.cn (Zhang H))
} 
structure of LLOs and the modified LLOs show excellent rate and cycle performances [1].

Inspired by the above considerations, a spinel-coexisting structure was designed based on the facile gas-solid reaction between phosphine and LLOs. Solid sodium hypophosphite was used as the phosphine source, which was low-cost and readily available. Phosphine reacted with oxygen at the surface of LLOs, which induced the increase of oxygen vacancies and the formation of spinel phase. As a result, the oxygen release was inhibited and $\mathrm{Li}$ ion conductivity was enhanced effectively after $\mathrm{PH}_{3}$ treatment. The modified LLOs (LLO@P) delivered an outstanding rate performance of $156.7 \mathrm{~mA} \mathrm{hg}^{-1}$ at a current density of $10 \mathrm{C}\left(1 \mathrm{C}=200 \mathrm{~mA} \mathrm{~g}^{-1}\right)$, much higher than that of pristine LLOs $\left(128.0 \mathrm{~mA} \mathrm{~h} \mathrm{~g}^{-1}\right)$. Moreover, LLO@P also exhibited an excellent cycle performance with a capacity retention of $74.0 \%$ after 300 cycles at $5 \mathrm{C}$, whereas the capacity retention of LLOs was only $54.4 \%$ under the same condition. The enhanced electrochemical performance can be attributed to the modified surface structure by phosphine.

\section{EXPERIMENTAL SECTION}

\section{Synthesis of pristine LLOs}

In a typical process [1], LLOs $\left(\mathrm{Li}_{1.2} \mathrm{Ni}_{0.13} \mathrm{Co}_{0.13} \mathrm{Mn}_{0.54} \mathrm{O}_{2}\right.$, which could also be written as $0.5 \mathrm{Li}_{2} \mathrm{MnO}_{3} \cdot 0.5 \mathrm{LiNi}_{0.333^{-}}$ $\mathrm{Co}_{0.333} \mathrm{Mn}_{0.333} \mathrm{O}_{2}$ ) were synthesized by oxalic acid coprecipitation, followed by hydrothermal as well as calcination processes. Stoichiometric amounts of $\mathrm{Ni}\left(\mathrm{CH}_{3}\right.$ $\mathrm{COO})_{2} \cdot 4 \mathrm{H}_{2} \mathrm{O}, \mathrm{Mn}\left(\mathrm{CH}_{3} \mathrm{COO}\right)_{2} \cdot 4 \mathrm{H}_{2} \mathrm{O}, \mathrm{Co}\left(\mathrm{CH}_{3} \mathrm{COO}\right)_{2}$. $4 \mathrm{H}_{2} \mathrm{O}$ and an excess amount of $\mathrm{CH}_{3} \mathrm{COOLi} \cdot 2 \mathrm{H}_{2} \mathrm{O}(10 \%$ molar ratio) were all dissolved in ethanol. The resulting solution (named solution A) was stirred at room temperature for $0.5 \mathrm{~h}$. Solution B was prepared by dropwise adding oxalic acid to solution A. Then, solution B was transferred to a Teflon-lined stainless steel autoclave and heated at $180^{\circ} \mathrm{C}$ for $12 \mathrm{~h}$. After that, the precipitate was collected by vacuum filtration and dried at $120^{\circ} \mathrm{C}$ for $3 \mathrm{~h}$. Then, it was pressed into plates and first annealed in air at $450^{\circ} \mathrm{C}$ for $5 \mathrm{~h}$ and then sintered in air at $850^{\circ} \mathrm{C}$ for $15 \mathrm{~h}$. Finally, the LLOs were obtained after gridding carefully.

\section{Synthesis of LLO@P}

First, LLOs and sodium hypophosphite were separately placed in a tailor-made glass reactor, as shown in Fig. S2. Then the reactor was sealed by an alcohol blast burner with the assistance of a vacuum pump to avoid interference of air and loss of phosphine. Finally, the glass reactor was heated for the desired time at a specific temperature to conduct the gas-solid reaction and LLO@P were obtained without further treatment.

\section{Material characterizations}

Powder X-ray diffraction (XRD) patterns of the cathode materials were obtained with a Rigaku D/max-2500 diffractometer using $\mathrm{Cu} \mathrm{Ka}$ radiation. Rietveld refinements were executed by General Structure Analysis System (GSAS) software package. The microstructure and element mapping of the material were analyzed by using a transmission electron microscope (JEM-2800). The electronic states of the sample were analyzed by X-ray photoelectron spectroscopy (XPS) on Escalab 250Xi spectrometer (Thermo Scientific). Raman spectra were collected using a Renishaw InVia Raman spectrometer with a wavelength of $514.5 \mathrm{~nm}$.

\section{Electrochemical measurements}

CR2430 coin-type cells were assembled for electrochemical measurement and characterization. Specifically, the as-prepared cathode materials, Super P carbon black and polyvinylidene fluoride (PVDF) in 8:1:1 mass ratio were mixed in $\mathrm{N}$-methyl-2-pyrrolidone to form a homogeneous slurry, which was then coated onto aluminum foil. The electrode sheet was dried at $60^{\circ} \mathrm{C}$ for $3 \mathrm{~h}$ and $150^{\circ} \mathrm{C}$ for $1 \mathrm{~h}$ under vacuum. Then, it was pressed and cut into discs with a radius of $6 \mathrm{~mm}$. The mass loading of active material was about $2.5 \mathrm{mg} \mathrm{cm}^{-2}$. Then, CR 2430 coin-type cells were assembled in an Ar-filled glove box. The cells consisted of the as-prepared cathodes, Li metal anodes, Celgard 2325 separators and electrolyte $\left(1 \mathrm{~mol} \mathrm{~L}^{-1} \mathrm{LiPF}_{6}\right.$ in a $1: 1 \mathrm{vol} \%$ ethylene carbonate (EC)-dimethyl carbonate (DMC) mixture). Galvanostatic charge/discharge tests were conducted at specific rates on a battery test system (LAND CT2001A model, Wuhan LAND Electronics. Ltd.). Cycle voltammetry measurements were performed with a scanning rate of $0.05 \mathrm{mV} \mathrm{s}^{-1}$ on Autolab system (Metrohm). Electrochemical impedance spectroscopy (EIS) was conducted on the same electrochemical workstation and the test frequency ranged from $100 \mathrm{kHz}$ to $0.01 \mathrm{~Hz}$.

\section{RESULTS AND DISCUSSION}

After optimizing the conditions (reaction time, reaction temperature and $\mathrm{PH}_{3}$ content, the details are given in the Supplementary Information) for the gas-solid reaction, it was found that LLO@P obtained with a $\mathrm{PH}_{3}$ content of $0.3 \mathrm{mmol}$ at $250^{\circ} \mathrm{C}$ for $10 \mathrm{~h}$ exhibited the best electrochemical performance (Figs S3 and S4). As shown in Fig. 1a, LLO@P delivered a high reversible capacity of 

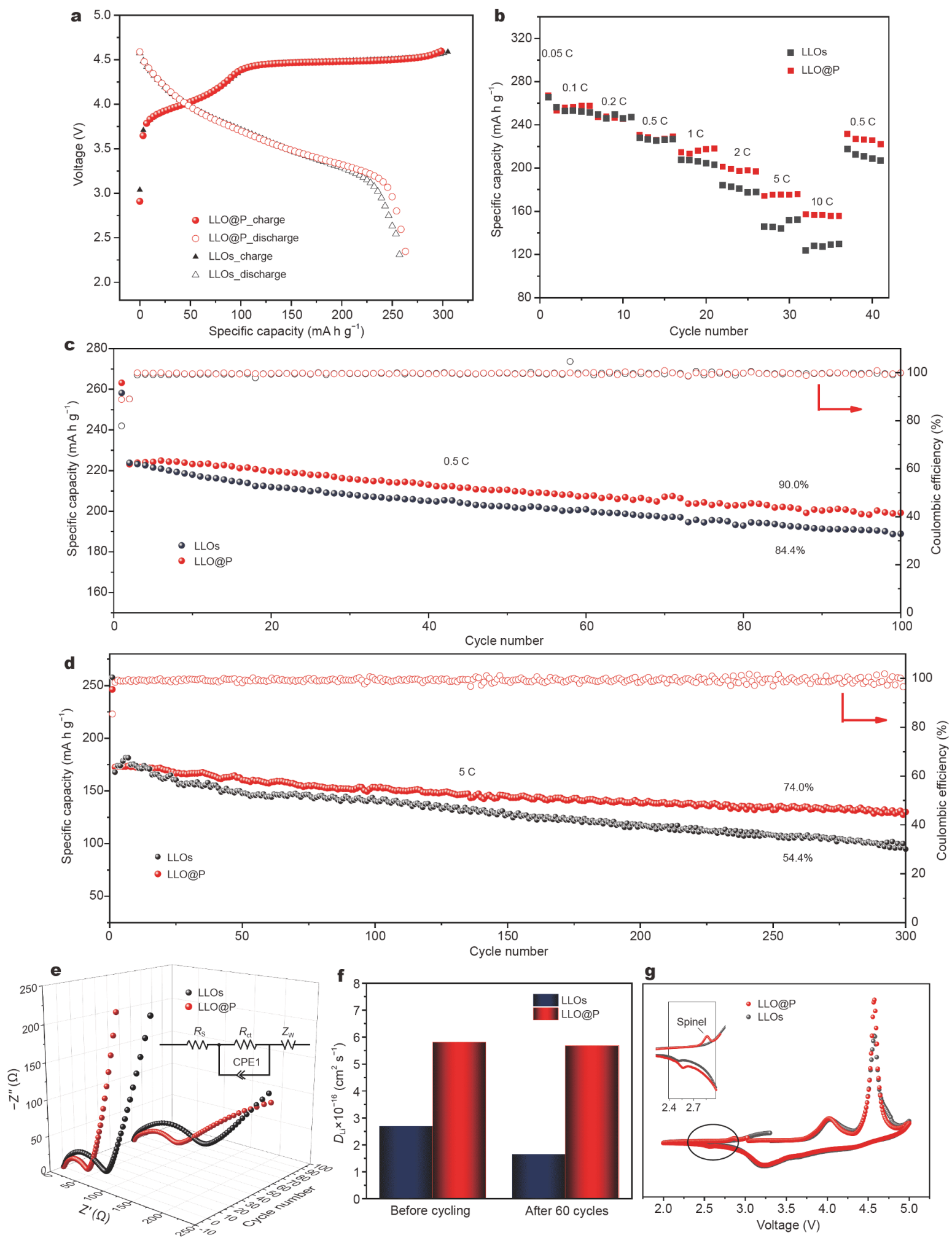

Figure 1 (a) Initial charge-discharge curves at $0.05 \mathrm{C}$, (b) high rate performance of LLOs and LLO@P. Cycling performance at (c) $0.5 \mathrm{C}$ and (d) 5 C, (e) EIS plots, (f) lithium ion diffusion coefficient of LLOs and LLO@P before cycling and after 60 cycles at 0.5 C, (g) CV profiles of LLOs and LLO@P. 
$267.4 \mathrm{~mA} \mathrm{~h} \mathrm{~g}^{-1}$ and a superior initial coulombic efficiency of $89.1 \%$ at $0.05 \mathrm{C}$, higher than that of pristine LLOs (260.8 $\left.\mathrm{mA} \mathrm{h} \mathrm{g}^{-1}, 84.5 \%\right)$. Moreover, LLO@P also exhibited excellent rate performance. At $0.1,0.2,0.5,1,2,5$ and $10 \mathrm{C}$, the discharge capacities of LLO@P were 257.8, 246.5, 226.9, 216.0, 199.3, 175.6 and $156.7 \mathrm{~mA} \mathrm{~h} \mathrm{~g}^{-1}$ (Fig. 1b), respectively. In contrast, pristine LLOs showed lower discharge capacities of 253.1, 246.0, 226.5, 206.1, 180.9, 151.9 and $128.0 \mathrm{~mA} \mathrm{~h} \mathrm{~g}^{-1}$ at the same rates. When the test current density reduced back to $0.5 \mathrm{C}$, LLO@P recovered its capacity, which indicated that the structure of LLO@P was stable after treatment. After 100 cycles at 0.5 C, LLO@P retained a remarkable discharge capacity of $199.2 \mathrm{~mA} \mathrm{~h} \mathrm{~g}^{-1}$ with a capacity retention of $90.0 \%$, whereas LLOs only retained $188.9 \mathrm{~mA} \mathrm{~h} \mathrm{~g}^{-1}$ with a capacity retention of $84.4 \%$ under the same conditions (Fig. 1c). Even at higher current density (5 C), LLO@P retained a discharge capacity of $131.1 \mathrm{~mA} \mathrm{~h} \mathrm{~g}^{-1}$ after 300 cycles with a capacity retention of $74.0 \%$ (Fig. 1d), which was much higher than those of pristine LLOs (96.1 $\mathrm{mA} \mathrm{h}^{-1}$ and 54.4\%).

Fig. 1e and $\mathrm{f}$ show the EIS results of LLO@P and LLOs before cycling and after 60 cycles. Both curves in Fig. 1e consist of a semicircle and a sloped straight line. The semicircle in intermediate frequency region is related to the charge transfer process and its diameter is proportional to the charge transfer resistance $\left(R_{\mathrm{ct}}\right)$. The other part in the low frequency region represents the solid-state diffusion of $\mathrm{Li}$ ions (Warburg impedance, $Z_{\mathrm{w}}$ ) in the ac- tive materials $[23,24]$. As shown in Table S1, $R_{\mathrm{ct}}$ values of LLO@P were much smaller than those of LLOs before and after cycling. Specifically, LLOs exhibited an $R_{\mathrm{ct}}$ value of $80.53 \Omega$ before cycling and $150.87 \Omega$ after 60 cycles, while the corresponding values for LLO@P were only 47.80 and $102.40 \Omega$ (Fig. S5). The Li ion diffusion coefficient $\left(D_{\mathrm{Li}}\right)$ was calculated based on the previous work [24]. It was found that $D_{\mathrm{Li}}$ increased from $2.68 \times 10^{-16}$ to $5.8 \times 10^{-16} \mathrm{~cm}^{2} \mathrm{~s}^{-1}$ after $\mathrm{PH}_{3}$ treatment. Moreover, the $D_{\mathrm{Li}}$ of LLO@P remained almost unchanged before cycling and after 60 cycles, whereas that of LLOs decreased from $2.68 \times 10^{-16}$ to $1.64 \times 10^{-16} \mathrm{~cm}^{2} \mathrm{~s}^{-1}$ under the same conditions (Fig. 1f). These results illustrated higher $\mathrm{Li}$ ion conductivity and structural stability for LLO@P, accounting for its excellent rate performance (Fig. 1b).

Cyclic voltammetry (CV) measurements of LLO@P and LLOs are shown in Fig. 1g. The CV curves of both LLO@P and LLOs showed two oxidation peaks at around 4.0 and $4.5 \mathrm{~V}$, which were related to the transition metal redox and $\mathrm{Li}_{2} \mathrm{MnO}_{3}$ activation processes, respectively. An extra redox peak appeared at $\sim 2.86 \mathrm{~V}$ in the $\mathrm{CV}$ curve of LLO@P, indicating the formation of spinel phase [20,25].

To further explore the effect of $\mathrm{PH}_{3}$ treatment, XRD, TEM, Raman and XPS analyses were conducted for both LLO@P and LLOs. The main crystal structure of LLO@P remained the same as that of pristine LLOs, which exhibited the same patterns as the previous work [26] (Fig. 2a, b and Fig. S6). The refinement results of LLO@P
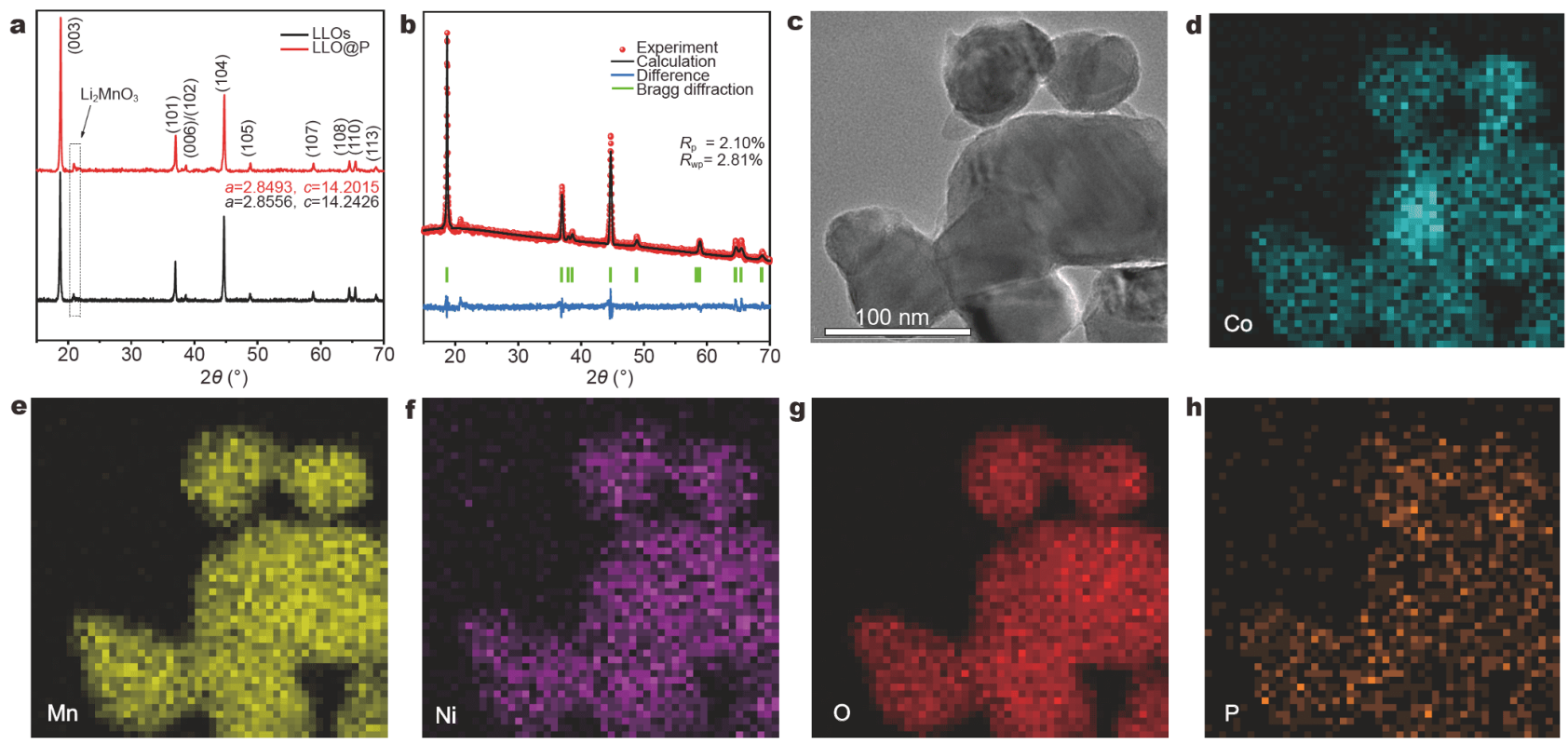

Figure 2 (a) XRD patterns of LLOs and LLO@P, (b) the refinement results of LLO@P. (c) TEM image of LLO@P and the EDS mapping of (d) Co, (e) $\mathrm{Mn},(\mathrm{f}) \mathrm{Ni},(\mathrm{g}) \mathrm{O}$ and (h) P. 
and the control sample LLOs exhibited similar unit cell parameters but a slight reduction of oxygen occupation (from 0.981 to 0.964 ) (Table S2), consistent with the fact that the gas-solid reaction occurred mainly at the surface of the materials rather than the bulk.

TEM-EDX analysis was performed to observe the effect of $\mathrm{PH}_{3}$ treatment on the morphologies of cathode materials (Fig. 2c-h and Fig. S7b-f). It can be seen that Co, $\mathrm{Mn}, \mathrm{Ni}$ and $\mathrm{O}$ elements were uniformly distributed in the LLOs and LLO@P cathode materials. Phosphorus was distributed homogeneously at the surface of the LLO@P cathode material, indicating the successful gas-solid reaction between $\mathrm{PH}_{3}$ and LLOs.

Fig. 3 and Fig. S7a present the high resolution TEM (HRTEM) images of LLO@P and LLOs, respectively. A set of lattice fringes with an interplanar spacing of about $0.4807 \mathrm{~nm}$ was observed in the TEM images of both LLO@P and LLOs, corresponding to the (003) layer of $R \overline{3} m$ in layered materials. It demonstrated that the bulk structure remained unchanged after $\mathrm{PH}_{3}$ treatment, which was in accordance with the results of XRD. Apart from the above (003) planes, there was another interplanar spacing of $0.2020 \mathrm{~nm}$ at the surface of LLO@P, which can be indexed to the (400) planes of spinel phase, indicating the formation of spinel layer [27-29].

Raman spectroscopy was carried out to further understand the structural difference between LLOs and LLO@P. As shown in Fig. 3c, the spectrum of LLOs consisted of two distinct peaks at around 475 and $593 \mathrm{~cm}^{-1}$, belonging to $E_{\mathrm{g}}$ bending vibration and $\mathrm{A}_{1 \mathrm{~g}}$ stretching vibration in layered structure, respectively $[3,30,31]$. There was an extra peak $\left(\sim 629 \mathrm{~cm}^{-1}\right)$ in the Raman spectrum of LLO@P (Fig. 3d), related to Mn-O vibration in the spinel structure [6,32]. This also demonstrated that a new spinel layer emerged at the surface region of LLO@P after $\mathrm{PH}_{3}$ treatment, which was consistent with the results of CV and HRTEM.

To explore the origin of spinel phase, XPS was carried out for LLOs and LLO@P. As seen from the XPS spectra of Ni $2 \mathrm{p}$ and Co $2 \mathrm{p}$ of the cathode materials (Fig. $4 \mathrm{a}$ and
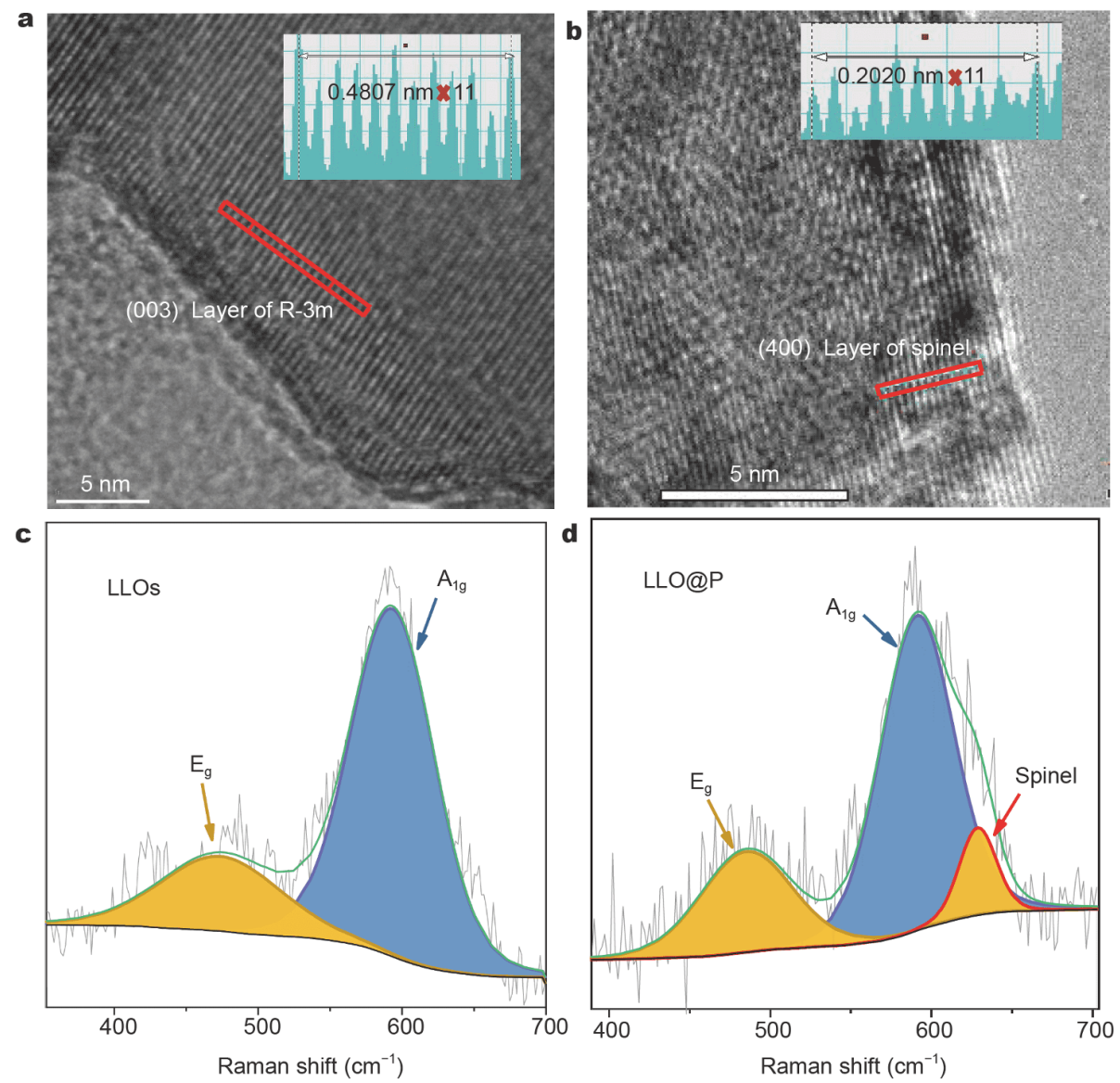

Figure 3 (a , b) The HR-TEM images of LLO@P. Raman spectra of (c) LLOs and (d) LLO@P. 

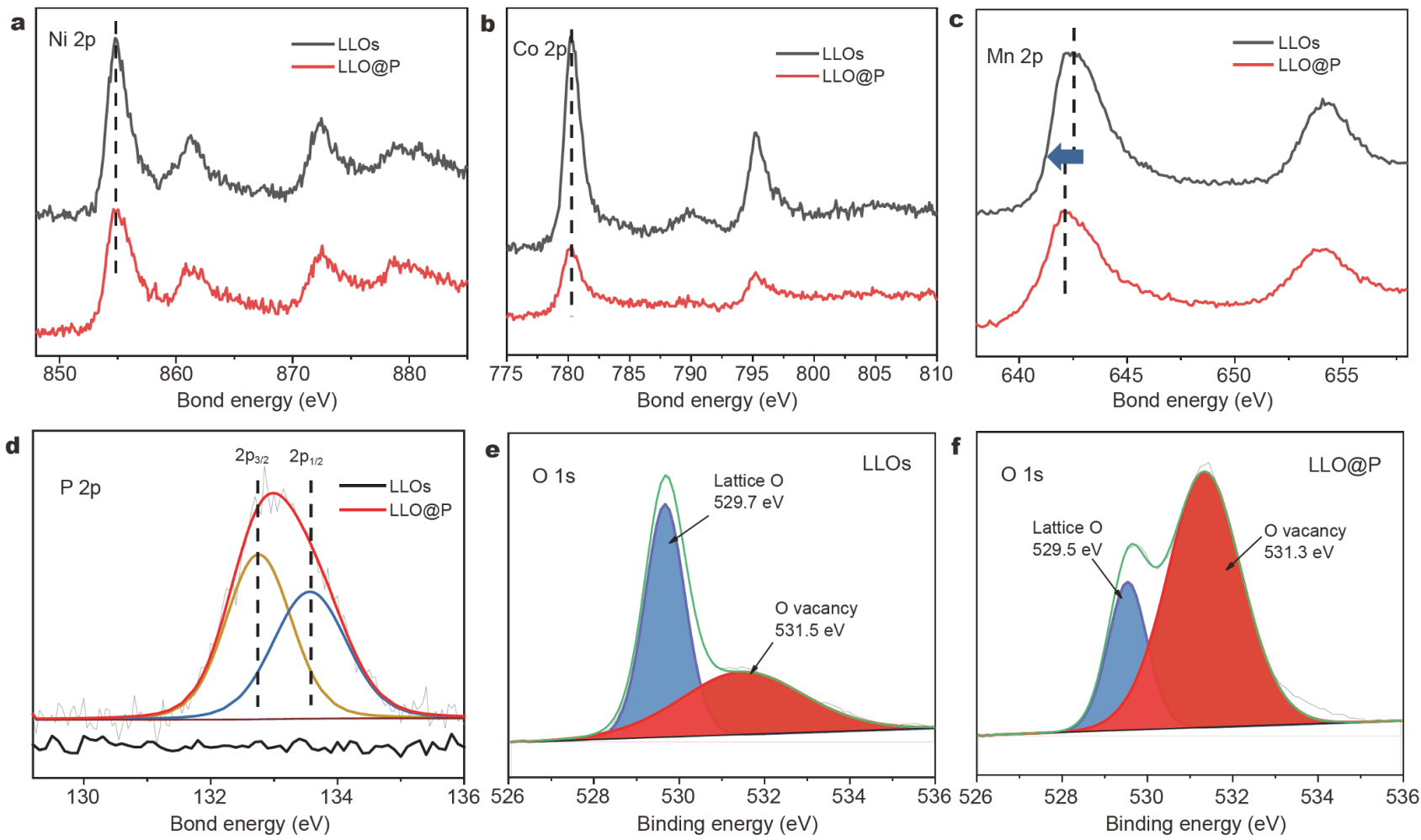

Figure 4 XPS spectra of (a) Ni, (b) Co, (c) Mn, and (d) P for LLOs and LLO@P. XPS spectra of O for (e) LLOs and (f) LLO@P.

b), there were two pronounced peaks at 854.85 and $780.17 \mathrm{eV}$, respectively, which coincided with those of $\mathrm{Ni}^{2+}$ and $\mathrm{Co}^{3+}$. The Mn $2 \mathrm{p}$ peak of pristine LLOs was located at $642.57 \mathrm{eV}$, which was assigned to $\mathrm{Mn}^{4+}$ [33] (Fig. 4c). After $\mathrm{PH}_{3}$ treatment, the Mn 2p peaks shifted to a lower binding energy region, meaning the reduction of $\mathrm{Mn}$. A pronounced peak emerged at around $133.0 \mathrm{eV}$ in the P 2p spectrum of LLO@P, indicating the gas-solid reaction between $\mathrm{PH}_{3}$ and LLOs. The phosphorus content in optimized LLO@P was estimated to be $\sim 0.75$ at.\% based on the inductively coupled plasma optical emission spectrometry (ICP-OES) results. O 1s spectra of LLOs and LLO@P are shown in Fig. 4e and f. There were two pronounced peaks at 529.7 and $531.5 \mathrm{eV}$ in Fig. $4 \mathrm{e}$ and f, corresponding to the lattice oxygen atoms $(\mathrm{O}-\mathrm{M}-\mathrm{O})$ and oxygen vacancies, respectively. In the $\mathrm{O} 1 \mathrm{~s}$ spectrum of LLO@P (Fig. 4f), the peak located at $531.3 \mathrm{eV}$ increased greatly, which indicated the increase of oxygen vacancies after $\mathrm{PH}_{3}$ treatment. This agreed well with the refinement results of XRD.

Combining the above results, the $\mathrm{PH}_{3}$ treatment process could be concluded in Fig. 5. First, sodium hypophosphite decomposed and released $\mathrm{PH}_{3}$ at specific temperature. Then, gaseous $\mathrm{PH}_{3}$ showed high reductivity and reacted with LLOs. This gas-solid reaction consumed reactive oxygen atoms at the surface region of LLOs, resulting in the formation of oxygen vacancies and the slight reduction of $\mathrm{Mn}$. As a result, a new spinel layer emerged at the surface region of LLOs, which significantly enhanced the rate performance of LLOs. Besides, the increase of oxygen vacancies also inhibited the oxygen release during cycling, suppressing the related side reactions and promoting the cycle performance of LLOs. Thus, the obtained LLO@P showed excellent electrochemical performance (Fig. 1).

\section{CONCLUSIONS}

In summary, a layered-spinel hybrid structure was prepared by a facile gas-solid $\mathrm{PH}_{3}$ treatment. It was found that $\mathrm{PH}_{3}$ reacted with the active oxygen atoms and lowered the oxygen partial pressure at the surface of LLOs. Thus, the oxygen release during cycling was effectively inhibited followed by reduced side reactions. Moreover, after $\mathrm{PH}_{3}$ treatment, the generated oxygen vacancies induced the phase transformation from layered structure to spinel structure at surface region, which enhanced the $\mathrm{Li}$ ion conductivity of LLO@P. As a result, the obtained LLO@P showed excellent cycle and rate performances 


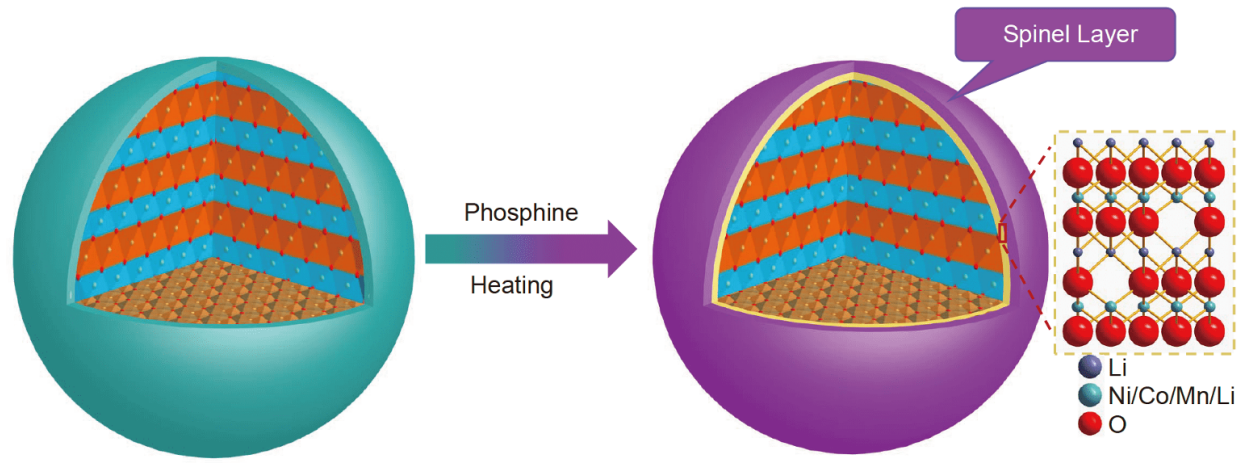

Figure 5 Schematic diagram of the $\mathrm{PH}_{3}$ treatment and structural components of the LLO@P.

simultaneously. At a high current density of $10 \mathrm{C}$, LLO@P showed a discharge specific capacity of $156.7 \mathrm{~mA} \mathrm{~h} \mathrm{~g}^{-1}$. After 300 cycles at $5 \mathrm{C}$, the capacity retention was as high as $74 \%$, much higher than that of pristine LLOs (54.4\%). Thus, the proposed method would be of importance to develop the cathode materials with high rate and long cycle performance.

Received 24 April 2020; accepted 19 June 2020; published online 8 September 2020

1 Sun $\mathrm{Z}, \mathrm{Xu} \mathrm{L}$, Dong $\mathrm{C}$, et al. A facile gaseous sulfur treatment strategy for Li-rich and Ni-rich cathode materials with high cycling and rate performance. Nano Energy, 2019, 63: 103887-103893

2 Lee J, Kitchaev DA, Kwon DH, et al. Reversible $\mathrm{Mn}^{2+} / \mathrm{Mn}^{4+}$ double redox in lithium-excess cathode materials. Nature, 2018, 556: 185190

3 Zhang XD, Shi JL, Liang JY, et al. Suppressing surface lattice oxygen release of li-rich cathode materials via heterostructured spinel $\mathrm{Li}_{4} \mathrm{Mn}_{5} \mathrm{O}_{12}$ coating. Adv Mater, 2018, 30: 1801751

4 Wang J, Sun X. Olivine $\mathrm{LiFePO}_{4}$ : the remaining challenges for future energy storage. Energy Environ Sci, 2015, 8: 1110-1138

5 Sui D, Xu L, Zhang H, et al. A 3D cross-linked graphene-based honeycomb carbon composite with excellent confinement effect of organic cathode material for lithium-ion batteries. Carbon, 2019, 157: 656-662

6 Yu FD, Que LF, Xu CY, et al. Dual conductive surface engineering of Li-rich oxides cathode for superior high-energy-density Li-ion batteries. Nano Energy, 2019, 59: 527-536

7 Sun Z, Xu L, Dong C, et al. Enhanced cycling stability of borondoped lithium-rich layered oxide cathode materials by suppressing transition metal migration. J Mater Chem A, 2019, 7: 3375-3383

8 Zhao E, Yu X, Wang F, et al. High-capacity lithium-rich cathode oxides with multivalent cationic and anionic redox reactions for lithium ion batteries. Sci China Chem, 2017, 60: 1483-1493

9 Yi L, Liu Z, Yu R, et al. Li-rich layered/spinel heterostructured special morphology cathode material with high rate capability for Li-ion batteries. ACS Sustain Chem Eng, 2017, 5: 11005-11015

10 Ma Y, Liu P, Xie Q, et al. Double-shell Li-rich layered oxide hollow microspheres with sandwich-like carbon@spinel@layered@spinel@carbon shells as high-rate lithium ion battery cathode. Nano Energy, 2019, 59: 184-196
11 Zheng J, Xu P, Gu M, et al. Structural and chemical evolution of Li- and Mn-rich layered cathode material. Chem Mater, 2015, 27: 1381-1390

12 Zhang S, Chen J, Tang T, et al. A novel strategy to significantly enhance the initial voltage and suppress voltage fading of a $\mathrm{Li}$ - and Mn-rich layered oxide cathode material for lithium-ion batteries. J Mater Chem A, 2018, 6: 3610-3624

13 Zheng J, Myeong S, Cho W, et al. Li- and Mn-rich cathode materials: Challenges to commercialization. Adv Energy Mater, 2017, 7: 1601284

14 Yi TF, Han X, Yang SY, et al. Enhanced electrochemical performance of Li-rich low-Co $\mathrm{Li}_{1.2} \mathrm{Mn}_{0.56} \mathrm{Ni}_{0.16} \mathrm{Co}_{0.08-x} \mathrm{Al}_{x} \mathrm{O}_{2}(0 \leq x \leq 0.08)$ as cathode materials. Sci China Mater, 2016, 59: 618-628

15 Nayak PK, Erickson EM, Schipper F, et al. Review on challenges and recent advances in the electrochemical performance of high capacity Li- and Mn-rich cathode materials for Li-ion batteries. Adv Energy Mater, 2017, 8: 1702397

16 Fu Q, Du F, Bian X, et al. Electrochemical performance and thermal stability of $\mathrm{Li}_{1.18} \mathrm{Co}_{0.15} \mathrm{Ni}_{0.15} \mathrm{Mn}_{0.52} \mathrm{O}_{2}$ surface coated with the ionic conductor $\mathrm{Li}_{3} \mathrm{VO}_{4}$. J Mater Chem A, 2014, 2: 7555-7562

17 Wang J, He X, Paillard E, et al. Lithium- and manganese-rich oxide cathode materials for high-energy lithium ion batteries. Adv Energy Mater, 2016, 6: 1600906

$18 \mathrm{Lu} \mathrm{Z}$, Dahn JR. Structure and electrochemistry of layered $\mathrm{Li}\left[\mathrm{Cr}_{x} \mathrm{Li}_{(1 / 3-x / 3)} \mathrm{Mn}_{(2 / 3-2 x / 3)}\right] \mathrm{O}_{2}$. J Electrochem Soc, 2002, 149: A1454

19 Cai $\mathrm{Y}, \mathrm{Ku} \mathrm{L}$, Wang $\mathrm{L}$, et al. Engineering oxygen vacancies in hierarchically Li-rich layered oxide porous microspheres for highrate lithium ion battery cathode. Sci China Mater, 2019, 62: 13741384

20 Erickson EM, Sclar H, Schipper F, et al. High-temperature treatment of Li-rich cathode materials with ammonia: improved capacity and mean voltage stability during cycling. Adv Energy Mater, 2017, 7: 1700708

21 Hy S, Felix F, Rick J, et al. Direct In situ observation of $\mathrm{Li}_{2} \mathrm{O}$ evolution on Li-rich high-capacity cathode material, $\mathrm{Li}\left[\mathrm{Ni}_{x} \mathrm{Li}_{(1-2 x) / 3} \mathrm{Mn}_{(2-x) / 3}\right] \mathrm{O}_{2}(0 \leq x \leq 0.5)$. J Am Chem Soc, 2014, 136: 999-1007

22 Qiu B, Zhang M, Wu L, et al. Gas-solid interfacial modification of oxygen activity in layered oxide cathodes for lithium-ion batteries. Nat Commun, 2016, 7: 12108

23 Han S, Qiu B, Wei Z, et al. Surface structural conversion and electrochemical enhancement by heat treatment of chemical predelithiation processed lithium-rich layered cathode material. J 
Power Sources, 2014, 268: 683-691

24 Shi S, Wang $\mathrm{T}$, Cao $\mathrm{M}$, et al. Rapid self-assembly spherical $\mathrm{Li}_{1.2} \mathrm{Mn}_{0.56} \mathrm{Ni}_{0.16} \mathrm{Co}_{0.08} \mathrm{O}_{2}$ with improved performances by microwave hydrothermal method as cathode for lithium-ion batteries. ACS Appl Mater Interfaces, 2016, 8: 11476-11487

25 Park S, Kang S, Johnson C, et al. Lithium-manganese-nickel-oxide electrodes with integrated layered-spinel structures for lithium batteries. Electrochem Commun, 2007, 9: 262-268

26 Zhang X, Yu R, Huang Y, et al. The influences of surface coating layers on the properties of layered/spinel heterostructured Li-rich cathode material. ACS Sustain Chem Eng, 2018, 6: 12969-12979

27 Wu B, Yang X, Jiang X, et al. Synchronous tailoring surface structure and chemical composition of Li-rich-layered oxide for high-energy lithium-ion batteries. Adv Funct Mater, 2018, 28: 1803392

$28 \mathrm{Ku} \mathrm{L}, \mathrm{Cai} \mathrm{Y}, \mathrm{Ma} \mathrm{Y}$, et al. Enhanced electrochemical performances of layered-spinel heterostructured lithium-rich $\mathrm{Li}_{1.2} \mathrm{Ni}_{0.13} \mathrm{Co}_{0.13}$ $\mathrm{Mn}_{0.54} \mathrm{O}_{2}$ cathode materials. Chem Eng J, 2019, 370: 499-507

29 Xia Q, Zhao X, Xu M, et al. A Li-rich layered@spinel@carbon heterostructured cathode material for high capacity and high rate lithium-ion batteries fabricated via an in situ synchronous carbonization-reduction method. J Mater Chem A, 2015, 3: 3995-4003

30 Zheng Y, Chen L, Su Y, et al. An interfacial framework for breaking through the $\mathrm{Li}$-ion transport barrier of Li-rich layered cathode materials. J Mater Chem A, 2017, 5: 24292-24298

31 Julien CM, Massot M. Lattice vibrations of materials for lithium rechargeable batteries III. Lithium manganese oxides. Mater Sci Eng-B, 2003, 100: 69-78

32 Meng F, Guo $\mathrm{H}$, Wang Z, et al. Modification by simultaneously $\gamma$ $\mathrm{WO}_{3} / \mathrm{Li}_{2} \mathrm{WO}_{4}$ composite coating and spinel-structure formation on $\mathrm{Li}\left[\mathrm{Li}_{0.2} \mathrm{Mn}_{0.54} \mathrm{Ni}_{0.13} \mathrm{Co}_{0.13}\right] \mathrm{O}_{2}$ cathode via a simple wet process. J Alloys Compd, 2019, 790: 421-432

33 Niu B, Li J, Liu Y, et al. Re-understanding the function mechanism of surface coating: modified Li-rich layered $\mathrm{Li}_{1.2} \mathrm{Mn}_{0.54} \mathrm{Ni}_{0.13} \mathrm{Co}_{0.13} \mathrm{O}_{2}$ cathodes with $\mathrm{YF}_{3}$ for high performance lithium-ions batteries. Ceramics Int, 2019, 45: 12484-12494

Acknowledgements The authors gratefully acknowledge the financial support from the Ministry of Science and Technology of China (MoST, 2016YFA0200200), the National Natural Science Foundation of China (NSFC, 21421001 and 51633002), Tianjin city (16ZXCLGX00100) and 111 Project (B12015).

Author contributions Chen $\mathrm{Y}$ conceived and designed the research; $\mathrm{Xu} \mathrm{L}$ fabricated the cathode materials and assembled the cells; Sun $\mathrm{Z}$ conducted partial characterization and analyses; Zhu Y, Han Y, Wu M, $\mathrm{Ma} \mathrm{Y}$ and Huang $\mathrm{Y}$ were involved in some experiments; Xu L and Zhang $\mathrm{H}$ wrote the paper, with support from Chen $\mathrm{Y}$; Chen $\mathrm{Y}$ and Zhang $\mathrm{H}$ coordinated the study. All authors contributed to the general discussion.

Conflict of interest The authors declare that they have no conflict of interest.

Supplementary information Experimental details and supporting data are available in the online version of the paper.

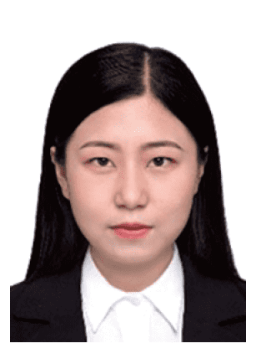

Lingqun $\mathbf{X u}$ received her BS degree in polymer material and engineering from Yanshan University. Now as a postgraduate in Nankai University, her research mainly focuses on improving the electrochemical performances of lithium-rich cathode materials and lithium sulfur batteries.

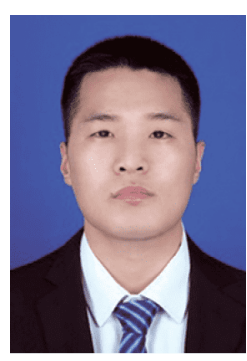

Zhenhe Sun received his BE and BS degrees from the Molecular Science and Engineering department of Nankai University in 2015. He is currently studying for a doctoral degree in Prof. Yongsheng Chen's Group. His research interests include the syntheses and modifications of lithium-rich cathode materials and supercapacitors based on carbon materials.

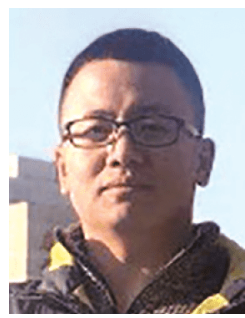

Hongtao Zhang received his $\mathrm{PhD}$ degree from the Institute of Chemistry, Chinese Academy of Sciences (ICCAS) in 2012. He joined Prof. Yongsheng Chen's group at Nankai University in 2014. His current research interests mainly focus on the syntheses and characterizations of organic and polymer functional materials and their applications in energy conversion and storage devices.

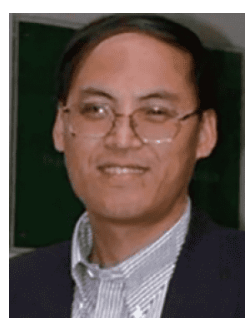

Yongsheng Chen graduated from the University of Victoria with a PhD degree in chemistry in 1997 and then joined the University of Kentucky and the University of California at Los Angeles for postdoctoral studies from 1997 to 1999. From 2003, he has been a Chair Professor at Nankai University. His main research interests include: i) carbon-based nanomaterials, including carbon nanotubes and graphene; ii) organic and polymeric functional materials, and iii) energy devices including organic photovoltaics and supercapacitors.

\section{通过气固反应制备高容量和高倍率性能的层状- 尖晶石复合正极材料 \\ 徐灵群 ${ }^{1,3 \dagger}$, 孙振贺 ${ }^{2 \dagger}$, 朱玉 ${ }^{2}$, 韩宇 $^{2}$, 吴蔓蔓 ${ }^{2}$, 马延风 ${ }^{2,3}$, 黄毅 ${ }^{3}$, 张洪涛, ${ }^{2,}$, 陈永胜 2,3}

摘要 富锂材料具有较高的比容量和能量密度, 因而受到了广泛关 注. 但是富锂材料仍然面临着库伦效率低、动力学性能差以及结 构稳定性差等缺点, 限制了其进一步的商业化应用. 本文中通过气 相的磷化氢对富锂材料进行热处理, 来提高其倍率性能和循环稳 定性. 在热处理过程中, 具有较高还原活性的磷化氢会与富锂材料 的表面活性氧原子进行反应, 进而在材料表面生成氧空穴和尖晶 石相结构. 改性后, 富锂材料的锂离子电导率和结构稳定性显著提 升, 当以 $10 \mathrm{C}$ 的大电流进行充放电时, 放电比容量可达 $156.7 \mathrm{~mA} \mathrm{~h} \mathrm{~g}^{-1}$, 在 5 C下循环 300 圈后容量保持率仍然可达 $74 \%$. 